\title{
Profile of Birth Injuries in a Tertiary Hospital in Enugu, Nigeria
}

\author{
Chukwubuike Kevin Emeka ${ }^{1,}$, Ekwochi Uchenna ${ }^{2}$, Enebe Joseph Tochukwu ${ }^{3}$, \\ Nduagubam Obinna Chukwuebuka ${ }^{2}$, Eze Thaddeus Chikaodili ${ }^{1}$, Iheji Chukwunonso Chigozie ${ }^{2}$ \\ ${ }^{1}$ Department of Surgery, Enugu State University Teaching Hospital, Enugu, Nigeria \\ ${ }^{2}$ Department of Pediatrics, Enugu State University Teaching Hospital, Enugu, Nigeria \\ ${ }^{3}$ Department of Obstetrics and Gynecology, Enugu State University Teaching Hospital, Enugu, Nigeria
}

Email address:

chukwubuikeonline@yahoo.com (C. K. Emeka)

${ }^{*}$ Corresponding author

\section{To cite this article:}

Chukwubuike Kevin Emeka, Ekwochi Uchenna, Enebe Joseph Tochukwu, Nduagubam Obinna Chukwuebuka, Eze Thaddeus Chikaodili, Iheji Chukwunonso Chigozie. Profile of Birth Injuries in a Tertiary Hospital in Enugu, Nigeria. American Journal of Biomedical and Life Sciences. Vol. 7, No. 5, 2019, pp. 99-103. doi: 10.11648/j.ajbls.20190705.11

Received: August 31, 2019; Accepted: September 16, 2019; Published: October 7, 2019

\begin{abstract}
Background: Birth injury is defined as structural damage of a newborn secondary to mechanical forces that occur during labor and/or delivery. This study determined the incidence, risk factors and outcome of birth injury. Methodology: This was an observational study of birth injuries in neonates, over a period of one year, carried out at a tertiary hospital in Enugu, south east, Nigeria. Results: Out of the 1,735 births recorded during the period of the study, there were 19 cases of birth injuries. This gave an incidence of 11 per 1000 live births. No neonate had more than one injury. They were thirteen males and six females that sustained birth injury. Cephalohematoma was the most common birth injury. Others are caput succedaneum, clavicular fracture, Erb's palsy, femoral fracture, humeral fracture, shoulder dislocation and facial laceration. Mode of delivery, neonatal birth weight, gestational age and maternal parity were significant predictive risk factors for birth injury. Conclusion: In the current study, cephalohematoma was the most common birth injury, followed by caput succedaneum. There is need to reduce the morbidity and mortality associated with birth injuries.
\end{abstract}

Keywords: Birth Injury, Incidence, Predictive Factor, Cephalohematoma

\section{Introduction}

Birth injury, which is also known as birth trauma, could be defined as structural damage of a newborn secondary to mechanical forces (such as compression or traction) that occurred during labour, delivery or both. It usually occurs as a result of physical pressure during the process of birth, as the fetus passes through the birth canal. Birth injury can be avoidable or inevitable [1]. The incidence of birth trauma varies widely and depends on the mode of delivery, fetal presentation and type of injury. Reported incidence ranges from 0.2 to 41.2 per 1000 live births [1]. The incidence rate of birth trauma may never by zero because birth trauma still occurs in optimal condition, in best of obstetrical care and even in the absence of any risk factors [2]. However, improved obstetric care has resulted in reduction in the incidence of birth trauma [3]. Though prenatal interventions such as amniocentesis and intrauterine transfusion may cause injuries to the fetus, they are not considered as birth injury [4]. The risk factors for birth trauma can be classified into three broad categories: Fetal factors, maternal factors and delivery mechanism. Fetal factors include macrosomia, abnormal fetal presentation and prematurity. These increase the chances of occurrence of birth trauma. Maternal factors include age, number of pregnancies and pelvic anatomy. Extreme maternal ages (less than 16 and greater than 35 years), primigravida, cephalopelvic disproportion, short maternal stature and maternal pelvic abnormalities predispose the fetus to birth injuries. Delivery mechanisms include obstetric instrumental techniques such as forceps and vacuum assisted delivery. These instruments increase the ease of descent of the fetus but also increase birth injury risk 
[4]. Birth injury may be mild such as caput succedaneum but can be severe and fatal such as intracranial bleeding. Considering the mortality and morbidity associated with birth injury and paucity of studies in Enugu, south eastern, Nigeria, it has become necessary to study birth injuries. The aim of this study was to determine the incidence, risk factors and outcome of birth injury in a tertiary hospital in Enugu, south east Nigeria.

\section{Methodology}

This was an observational study carried out at Enugu State University Teaching Hospital (ESUTH), Enugu. This study lasted over a period of one year, from June $1^{\text {st }}$ to May $31^{\text {st }} 2018$. Babies delivered at ESUTH during the study period and babies that have birth injuries, who were referred from peripheral hospital, were recruited for the study. Stillbirths were excluded from the study. Enugu State University Teaching Hospital is located in Enugu, south east Nigeria. The hospital serves the whole of Enugu state. Enugu state, according to 2016 estimates of the National Population Commission and Nigerian National Bureau of Statistics, has a population of about 4 million people and a population density of $616.0 / \mathrm{km}^{2}$. Referrals are also received from neighboring states. Diagnosis of birth injury was made based on full physical examination by the pediatrician, obstetrician or pediatric surgeon. Data were extracted from newborn special care units, labor wards, postpartum wards, case notes, operation notes, operation register, and admission-discharge records. Medical records from a control group of uninjured babies born during the same period were also reviewed for comparison. The information extracted include maternal age, gender, parity, gestational age, birth weight, fetal presentation, mode of delivery, type of birth injury, treatment offered, duration of hospital stay and outcome. Ethical approval was obtained from the Ethics and Research committee of the hospital. Statistical Package for Social Science (SPSS) version 21 was used for data entry and analysis. Tables were used to present simple descriptive statistics, Student $\mathrm{t}$ - test was used to compare means between groups and Chi square test was used for testing association between categorical variables. P-value of $<0.05$ was considered statistically significant.

\section{Results}

\subsection{Demography}

During the period of the study, a total of 1,735 births were recorded and there were 19 newborns with varying degrees of trauma resulting from birth process. This gives an overall incidence of birth trauma of $1.1 \%$ or 11 per 1000 live births. No newborn had more than one birth injury. There were 13 males and 6 females, with a male to female ratio of $2: 1$. The mean gestational age of the babies who sustained birth injuries was $38.8 \pm 1.5$ weeks while their mean weight was $3.2 \pm 0.6$ kilograms $(\mathrm{kg})$. The mean age of the babies at presentation was $1.9 \pm 0.8$ days. Details of the patients' demographics are shown in table 1.

Table 1. Demographic characteristics of the patients.

\begin{tabular}{|c|c|c|c|}
\hline Demography & & Number & Percentage (\%) \\
\hline \multicolumn{4}{|l|}{ Gender } \\
\hline & Male & 13 & 68.4 \\
\hline & Female & 6 & 31.6 \\
\hline \multicolumn{4}{|c|}{ Gestational Age } \\
\hline & Preterm & 4 & 21.1 \\
\hline & Term & 12 & 63.2 \\
\hline & Postterm & 3 & 15.7 \\
\hline \multicolumn{4}{|l|}{ Weight } \\
\hline & $2.5 \mathrm{~kg}$ and below & 4 & 21.1 \\
\hline & Above $2.5 \mathrm{~kg}$ & 15 & 78.9 \\
\hline \multicolumn{4}{|c|}{ Age at Presentation } \\
\hline & Within 24 hours of birth & 6 & 31.6 \\
\hline & After 24 hours of birth & 13 & 68.4 \\
\hline
\end{tabular}

\subsection{Mode of Delivery}

Out of the 19 newborns that had birth injuries, 12 were delivered vaginally and 7 were delivered through caesarian section. Considering the mode of delivery, the incidence of birth injury was $0.7 \%$ for vaginal delivery and $0.4 \%$ for caesarian section (Table 2).

Table 2. Modes of delivery.

\begin{tabular}{lll}
\hline Route of delivery & Number & Specific incidence \\
\hline Vaginal delivery & 12 & 0.7 \\
Caesarian section & 7 & 0.4 \\
\hline
\end{tabular}

\subsection{Types of Birth Injuries}

The most common birth injury in our patients was cephalohematoma which occurred in 6 cases $(31.6 \%)$. Others are caput succedaneum $3(15.8 \%)$; clavicular fracture 3 (15.8\%); Erb's palsy 3 (15.8\%); femoral fracture $1(5.3 \%)$; humeral fracture $1(5.3 \%)$; shoulder dislocation 1 (5.3\%) and facial laceration $1(5.3 \%)$. None of the patients developed more than one birth trauma (Table 3)

Table 3. Birth injuries sustained.

\begin{tabular}{lll}
\hline Type of injury & Number & Percentage (\%) \\
\hline Cephalohematoma & 6 & 31.5 \\
Caput succedaneum & 3 & 15.8 \\
Clavicular fracture & 3 & 15.8 \\
Erb's palsy & 3 & 15.8 \\
Femoral fracture & 1 & 5.3 \\
Humeral fracture & 1 & 5.3 \\
Shoulder dislocation & 1 & 5.3 \\
Facial laceration & 1 & 5.3 \\
\hline
\end{tabular}

\subsection{Treatment Offered}

Most of the birth injuries were treated non-operatively $(89.5 \%)$. Only two patients $(10.5 \%)$ had operative treatment. One of the neonates that had cephalohematoma developed an abscess that required incision and drainage. The abscess resulted from local scarification of the swelling by the parents using a razor blade, before presenting to the hospital. The other birth injury that required operative treatment was the facial laceration that required suturing. 


\subsection{Complications Resulting from Birth Trauma}

Most of our patients (73.7\%) did not develop any complications while five patients $(26.3 \%)$ developed complications. Two patients, each $(10.5 \%)$, developed anemia and jaundice. One patient (5.3\%) developed sepsis (Table 4).

Table 4. Complications developed by the patients.

\begin{tabular}{lll}
\hline Complications & Number & Percentage (\%) \\
\hline Anemia & 2 & 10.5 \\
Jaundice & 2 & 10.5 \\
Sepsis & 1 & 5.3 \\
\hline
\end{tabular}

\subsection{Risk Factors Assessment}

The mean age and weight of the mothers whose babies have birth injuries was 34.4 years and 63.2 kilograms respectively. The mean age and weight of the mothers whose babies did not sustain birth injury was 34.9 years and 61.7 kilograms. Sixty percent of the mothers were aged 27 to 35 years and while sixty three percent weighed below 62 kilograms. Relating the ages and weights of the mothers whose children had birth injuries with those whose children did not have birth injury, gave a $\mathrm{p}$ value of 0.8 and 0.6 respectively, which are not statistically significant. For the mothers whose babies developed birth injuries, 47 percent of the women were multiparous while 53 percent were primiparous. Comparing the parity of the mothers whose children had birth injuries with those whose children did not have birth injury statistically resulted in a $\mathrm{p}$ value of 0.04 . Thirteen babies (68.4\%) presented cephalic while six (31.6\%) presented breech. Out of the 19 neonates that developed birth injuries, twelve were delivered vaginally while seven were delivered through caesarian section. All the breech presentations were delivered through caesarian section. When both fetal presentations were analyzed statistically, with respect to those that did not develop any birth trauma, the $\mathrm{p}$ value was 0.20 . Other predictive factors assessed are shown in Table 5.

Table 5. Predictive factors of birth injury.

\begin{tabular}{|c|c|c|c|}
\hline Variables & $\begin{array}{l}\text { Birth trauma } \\
\text { present }(\%)\end{array}$ & $\begin{array}{l}\text { Birth trauma } \\
\text { absent }(\%)\end{array}$ & $\begin{array}{l}\mathbf{p} \\
\text { value }\end{array}$ \\
\hline \multicolumn{4}{|l|}{ Gender } \\
\hline Male & 68.4 & 63.2 & \\
\hline Female & 31.6 & 36.8 & 0.30 \\
\hline \multicolumn{4}{|l|}{ Mode of delivery } \\
\hline Vaginal & 63.2 & 62.4 & \\
\hline Caesarian section & 36.8 & 37.6 & 0.04 \\
\hline Mean maternal age & 34.4 & 34.9 & 0.80 \\
\hline Mean maternal weight & 63.2 & 61.7 & 0.60 \\
\hline \multicolumn{4}{|l|}{ Parity } \\
\hline Multipara & 47 & 42.1 & \\
\hline Primipara & 53 & 57.9 & 0.04 \\
\hline \multicolumn{4}{|l|}{ Fetal presentation } \\
\hline Cephalic & 68.4 & 61.2 & \\
\hline Breech & 31.6 & 38.8 & 0.20 \\
\hline Gestational age (weeks) & 38.8 & 36.9 & 0.01 \\
\hline Birth weight (kg) & 3.2 & 2.6 & 0.03 \\
\hline
\end{tabular}

\subsection{Outcome}

The mean duration of hospital stay of the 19 babies that had birth injuries was 8 days. Eighteen patients (94.7\%) did well and were discharged. One patient $(5.3 \%)$ died as result of overwhelming sepsis from infected cephalohematoma.

\section{Discussion}

Birth injury can be described as any condition that adversely affects the fetus during labor or delivery. Management of birth injury should be multidisciplinary and involves the obstetricians, paediatricians, surgeons and physiotherapists [5]. The incidence of birth injury in our study population was $1.1 \%$ or 11 per 1000 live births which is consistent with the observation of some series [6-9]. However, an incidence as high as $14.7 \%$ and $22 \%$ have been reported $[10,11]$. These differences in the incidence of birth trauma could be explained by the type of injury studied and the setting of the study. There is male predominance in the current study. This finding is in conformity with other studies $[11,12]$. However, other studies reported female predominance with regards to birth injuries [7, 10]. These differences in gender predominance are difficult to explain but may be attributed to geographical locations since birth trauma varies from place to place. The mean gestational age of our patients is similar to the findings by Osinaike et al [11]. Awari et al reported a mean gestational age of 39 weeks in their study group [6].

In the present study, cephalohematoma was present in 31.6 per cent of live births. This was found to be the most common birth injury in our hospital. This finding is in agreement with other series on birth injuries [1, 8, 13-16]. But this finding is at variance with some other studies on birth injuries [7, 11-12]. Cephalohematoma results from subperiosteal collection of blood due to rupture of vessels beneath the periosteum. Most cases of cephalohematoma are unilateral due to the fact that bleeding does not cross the suture lines as it occurs within a single cranial plate [4]. The differences in the pattern of birth injury could be due to the mode of delivery and protocol for managing deliveries. Some tertiary hospitals have the protocol of performing caesarian section on all breach fetal presentation. The essence of this is to avoid birth trauma since it's been shown that birth trauma is less with caesarian section [1], [16]. The finding of the current study also supports this assertion. Most of our patients $(89.5 \%)$ were not operated upon. Other studies also reported non-operative treatment of birth injuries [17-18]. The management of birth injuries varies widely and depends on the type and severity of the injury. Twenty six percent of our patient in the current study developed complications such as anaemia, jaundice and sepsis as a result of the birth injury. This is similar to what Pius et al reported in their study [12].

On the risk assessment, there were more birth injuries in neonates who were delivered vaginally and this was found to be statistically significant. This stipulates that the risk of developing birth trauma is more during vaginal delivery. This 
finding is consistent with the report of other studies [13, 19]. However, Moczygemba et al reported that infants delivered by caesarean section are at risk of birth trauma when compared with infants delivered vaginally [20]. This finding by Moczygemba et al may be explained by the specific type of birth injuries they assessed in their study. Evaluating the mean gestational age of the babies that had birth injury (38.8 weeks) with the mean gestational age of babies that did not have birth injury (36.9 weeks) gave a $p$ value of 0.01 which is statistically significant. This entails that the higher the gestational age, the higher the chances of birth injury. Babies who sustained birth injuries also had higher birth weight (3.2 kilograms versus 2.6 kilograms), $p$ value $=0.03$. Borna et al also reported that higher birth weight and gestational weight were associated with birth injuries [15]. Njokanma et al documented that birth weight above 4 kilograms is associated with a higher risk of birth trauma [21]. Another factor analyzed for the occurrence of birth injury was the parity of the mothers. Most of the birth injuries occur in babies of primiparous women while babies of multiparous women sustained less number of birth injuries. Other studies support this finding $[1,11,22]$. However, Saemundur et al in their study stated that neonatal injuries are related to multiparity but maternal injuries are related to primiparity [23].

\section{Conclusion}

In the current study, cephalohematoma is the most common birth injury, followed by caput succedaneum. Amongst the factors analyzed, mode of delivery, neonatal birth weight, gestational age and maternal parity were found to be the predictive factors of birth injuries in the current study. This study was a hospital based study. The future lies in a community based study so that more birth injuries can be captured. It is recommended that every effort should be made to reduce the occurrence of birth injuries. We advise that macrosomic babies should be delivered through caesarian section and post datism should be avoided. Primiparous women should be well supervised during labor and offered caesarian section in circumstance of difficult or prolonged labor. These will reduce the occurrence of birth injuries.

\section{References}

[1] Abedzadeh - Kalahroudi M, Talebian A, Jahangiri M, Mesdaghinian E, Mohammadzadeh M. Incidence of Neonatal Birth Injuries and Related Factors in Kashan, Iran. Arch Trauma Res. 2015; 4 (1): e22831. doi: 10.5812/atr22831.

[2] Van Vleet M, Birth Related Injury. In: Elzouki A, Harfi H, Nazer H, Stapleton FB, Oh W, Whitley R, editors. Textbook of Clinical Pediatrics. Berlin Heidelberg: Springer; 2012. Pp 159-75.

[3] Parker LA. Part 1: Early recognition and treatment of birth trauma. Injuries to the head and face. Adv Neonatal Care. 2005; 5 (6): 289-97.

[4] Naomi Ojumah, Rebecca C Ramdhan, Charlotte Wilson,
Marios Loukas, Rod J Oskouian, Shane Tubbs R. Neurological Neonatal Birth Injuries: A Literature Review. Cureus. 2017; 9 (12): e1938. doi: 10.7759/cureus.1938.

[5] Hovind KH. Traumatic Birth Injuries. In: Raimondi AJ. Choux M, Di Rocco. Editors. Head injuries in the Newborn and infant. Principles of Pediatric Neurosurgery. Springer, New York, NY. doi: 10.1007/978-1-4615-7183-4_7.

[6] Awari BH, Al-Habdan I, Sadat Ali M, Al-Mulhim A. Birth associated trauma. Saudi Med J. 2003; 24 (6): 672-74.

[7] Ray S, Mondal R, Samanta M, Hazra A, Sabui TK, Debnath A, Chatterjeek K, Mukhopadhayau D, Sil A. Prospective Study of neonatal birth trauma: Indian perspective. 2016; 5 (2): 91 95. doi: 10.4103/2249-4847.179898.

[8] Hughes CA, Harley EH, Milmoe G, Bala R, Martorella A. Birth Trauma in the Head and Neck. Arch Otolaryyngol Head Neck Surg. 1999; 125: 193-199.

[9] Perlow JH, Wigton T, Hart J. Strassner HT, Nageotte MP, Wolk BM. Birth trauma. A five-year review of incidence and associated perinatal factors. J Reprod Med. 1996; 41 (10): 754-60.

[10] Cosmos Y, Cephas E, Adjoa NB, Seth KA, Nii KK, Eric KO. Prevalence and predisposing factors of brachial plexus birth palsy in a regional hospital in Ghana: a five year retrospective study. Pan Afr Med J. 2019; 32: 211. doi: 10.11604/pamj.2019.32.211.17914.

[11] Osinaike BO, Akinseye LO, Akiyode OR, Anyaebunam C, Kushimo O. Prevalence and Predictive factors of birth traumas in neonates presenting to the children emergency center of a tertiary center in Southwest, Nigeria. doi: 10. 4103/jcls.jcls_6216.

[12] Pius S, Ibrahim HA, Ibrahim BA, Farouk AG, Machoko Y, Bello M. Incidence and characteristics of neonatal birth injuries in Maiduguri North Eastern Nigeria. Niger J Paediatr. 2018; 45 (2): 99-105.

[13] Mosavat SA, Zamani M. The incidence of birth trauma among live born term neonates at a referral hospital in Rafsanjan Iran. J Matern Fetal Neonatal Med. 2008; 21 (5): 337-9. doi: $10.1080 / 14767050801927921$.

[14] Bhalla M, Srivastava AR, Srivastava JR, Bhalla JR, Pradhan K. Birth injuries in the Newborn. Indian J Pediatr. 1976; 43: 297.

[15] Borna H, Rad SM, Borna S, Mohseni SM. Incidence and risk factors for birth trauma in Iran. Taiwan J Obstet Gynecol. 2010; 49 (2): 170-3. doi: 10.1016/S1028-4559(10)60036-8.

[16] Linder N, Linder I, Fridman E, Konadio F, Lubin D, Meriob P, Yoger Y, Melamed N. Birth trauma-risk factors and short term neonatal outcome. J Matern Fetal Neonatal Med. 2013; 26 (15): 1491-5. doi: 10.3109/14767058.2013.789850.

[17] Fette A. Birth and Neonatal Care injuries. A Special Aspect of Newborn Surgery. Pediatr Therapeut. 2012; 2: 132. doi: 10.4172/2161-0665.1000132.

[18] Gangaram Akangire, Brian Carter. Birth Injuries in Neonates. Pediatrics in Review. 2016; 37: 451. doi: 10.1542/pir. 20150125 .

[19] Warke C, Malik S, Chockhandre M, Saboo A. Birth Injuries-A review of incidence, perinatal risk factors and outcome. Bombay Hosp J. 2012; 54 (2): 202-208. 
[20] Moczygemba CK, Paramsothy P, Meikle S, Kourtis AP, Barfield WD, Kaklina E, Posner SF, Whiteman MK, Jamieson DJ. Route of delivery and neonatal birth trauma. Am J Obstet Gynecol. 2010; 202 (4): doi: 10.1016/j.ajog.2009.11.041.

[21] Njokanma OF, Kehinde O. Mechanical Birth trauma-An Evaluation of predisposing factors at the Ogun State University Teaching Hospital Shagamu. Niger J Paediatr. 2012; 29 (3): 61-65.
[22] Prabhu RS, Sajjid M, Anandan H. Incidence and Predisposing Factors of Birth Trauma in a Tertiary Care Hospital in Chennai, India: A Prospective Study. Int J Sci Stud. 2017; 4 (10): 29-33.

[23] Saemundur Gudmundsson, Anne-Lindaqvist. Correlation of birth injury with maternal height and birth weight. BJOG; 112: 764-767. doi: 10.1111/j.1471-0528.2004.00545.x. 